\title{
Fire Separation between External Walls of Buildings
}

\author{
C. R. BARNETT \\ Macdonald Barnett Partners, Ltd. \\ P.O. Box 37-077 \\ Auckland, New Zealand
}

ABSTRACT

Most fire codes use only one or two radiation flux values when considering the external walls of buildings. If it is satisfactory to assume fire compartment temperatures are proportional to time, then it should be equally satisfactory to assume radiation flux levels are proportional to time. On this premise and using the standard time-temperature curve, a wider than usual range of design radiation values can be derived which are in step with standard FRR ratings. The method allows building designers more flexibility in the choice of ordinary or fire windows, both in "mirror-image" or "non mirror-image" situations.

INTRODUCTION

The paper focuses attention on the protection of "neighbour's property". Sub-divided into five categories, the hazards likely to cause a neighbour's property to be ignited by a burning building are:- external wall collapse; flying brands; flame contact; emitted heat radiation; received heat radiation. For the protection of the neighbour's property, certain steps need to be taken by the owners and different steps by the neighbours. The only way to provide mutual protection is to ensure that all buildings are built on the basis that during their lifetime they could be both an owner's (burning) building and a neighbour's (non-burning) building.

In a fire sense, an "external" wall is a special kind of wall that is different from ordinary internal walls, and may be different from fire walls and fire partitions. Within flame contact range, the external wall needs to function like a fire wall and cope with fire from both sides. Beyond flame contact range, but within radiation danger range, the external wall needs to cope with fire from inside and radiation on the outside.

It has long been recognised that the risk of fire spreading from one building to another reduces as the distance between them increases. Once the limiting radiation danger distance is exceeded no measures need to be taken for neighbour's property safety. Spreading risk can be eliminated if the buildings are far enough apart. In areas where no stored or running water may be available, such as rural areas, remote islands, or the Antarctic; this may be the only economic solution to fire spreading risks.

The aim of this paper is to provide a guide for building designers by setting out the principles for a "fire engineering design method for sepa- 
ration between buildings" which can be used in step with a "fire engineering design method for fire compartment areas" (to be published). Both design methods will encourage smaller fire compartments to be constructed, which can in turn reduce the cost of property lost by fire.

\section{MEANING OF "DISTANCE"}

Because either building can catch fire, the positions of owner and neighbour can be reversed and all wall criteria apply equally to both parties. That is, each building situation should be regarded as the "mirror-image" of the other as illustrated in Fig. 1. Where the owner has no control over the neighbour's construction, "mirror-imaging" or equal limiting distances may not occur but safety is not necessarily impaired as illustrated in Fig. 2. "Mirror-imaging" does not necessarily err on the side of safety for unequal limiting distances as illustrated in Fig. 3 . The meaning of distance is important in Fire code applications and needs to be clearly understood. For the purpose of this paper, the following definitions shall be used:-

a) radiation distance ( $R$ ) shall be the distance between the flame front of a burning building and the face of any exposed building.

b) separation distance (S) shall be the distance between the wall face of the burning building and the wall face of any exposed building.

c) limiting distance (L) shall be half the separation distance between the face of a burning building and the face of any exposed building.

a) protected limiting distance ( $L_{X}$ ) shall be a value of the limiting distance specified by the writers of the fire code in which fire resistance closures shall be mandatory.

e) flame projecting distance (P) shall be either 2 metres (or less if calculated in an approved manner under full wind conditions), or zero if suitable fire windows are installed.

\section{EXTERNAL WALL COLT.APSE}

In designing the owner's building, ignition of the neighbour's property by the ownex's wall collapse can be controlled by ensuring that any external wall of the owner's building within falling danger range (assumed as the height of the owner's wall), should remain standing for the duration of the fire to act as a heat barrier to prevent spread of fire to a neighbour's building. If any parts of the extexnal wall collapse too soon, projecting flame sizes may be increased and emitted radiation areas will certainly be increased. Both effects may cause an ignition of the neighbour's property which otherwise may not have occurred.

\section{FIYING BRANDS}

Combustible materials on or inside neighbouring buildings can be ignited from a fire by any of three forms of ignition termed "spontaneous", "pilot" and "contact" ignition respectively. The most common combustible material found on the exterior of buildings is wood and its ignition behaviour. when pre-heated by radiation is representative of a large variety of combustible building materials. Law (1963) quotes typical values of $\mathrm{rad}-$ iation intensities for pilot and spontaneous ignition of wood as $12.5 \mathrm{~kW} / \mathrm{m}^{2}$ $\left(0.3 \mathrm{cal} / \mathrm{cm}^{2} . \mathrm{s}\right)$ and $33.5 \mathrm{~kW} / \mathrm{m}^{2}\left(0.8 \mathrm{cal} / \mathrm{cm}^{2} . \mathrm{s}\right)$ respectively. Where a neighbouring building exterior does not have any combustible material on the exterior and has fire windows installed, neither contact ignition nor pilot ignition will apply and flying brands can be ignored. Where a neighbouring building has ordinary glazing in its windows liable to crack under radiant 


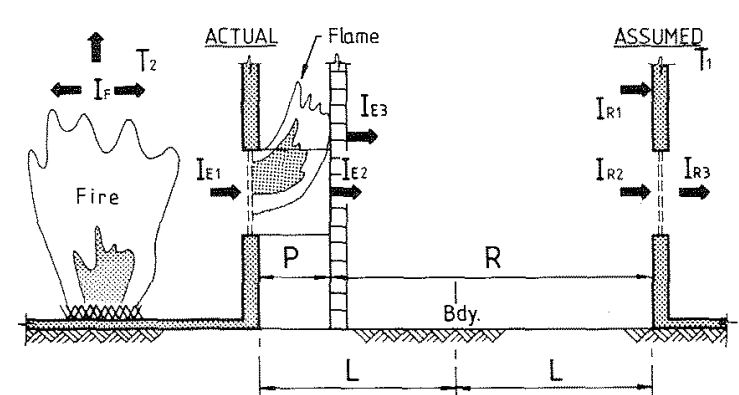

(a) QROINARY WINDOWS - MIRROR IMAGEO

$\stackrel{\infty}{\oplus}$

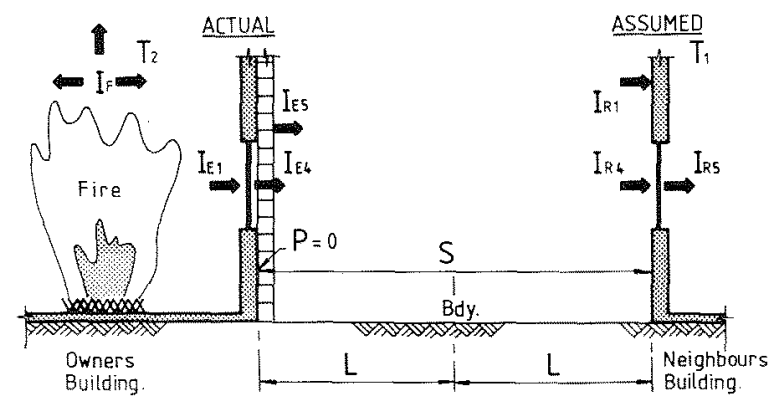

(b) FIRE WINDOWS - MIRROR IMAGED

FIG.1: DIAGRAMS ILLUSTRATING SEPARATION DISTANCES, FLAME PROJECTION DISTANCE P AND LIMITING DISTANCE L FOR ORDINARY WINDOWS AND FIRE WINDOWS RADIATION DISTANCE IS $R$.
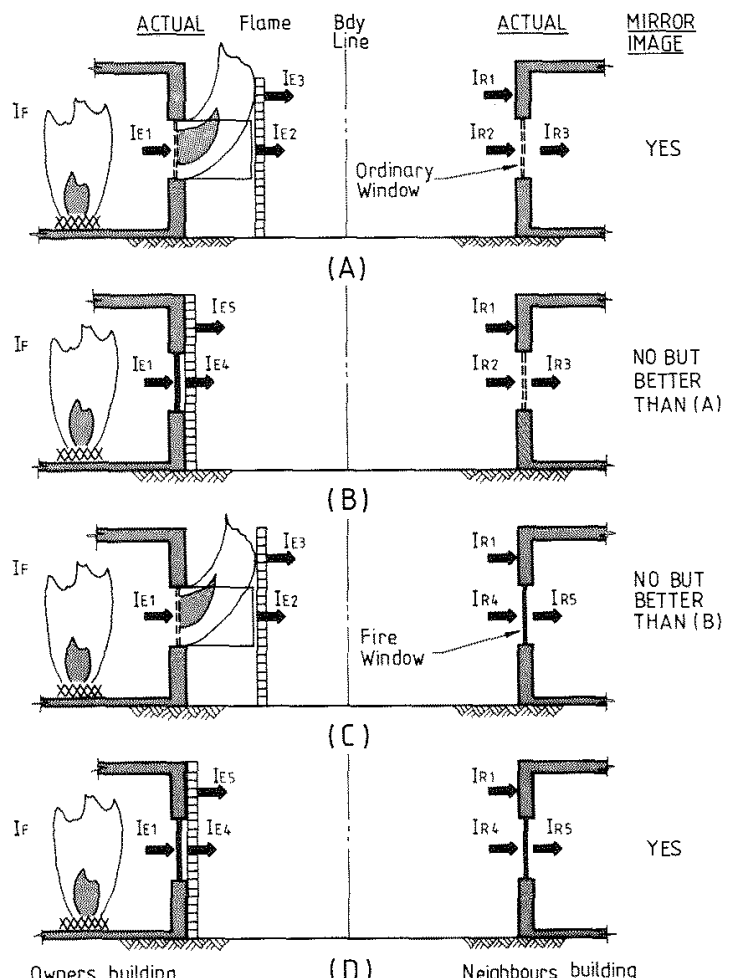

Owners building

(D)

Neightours building

FIG.2 DIAGRAM ILLUSTRATING DIFFERENCES BETWEEN ORDINARY \& FIRE WINDOWS AT EQUAL LIMITING DIST ANCE WHEN BASED ON "MIRROR IMAGING." 
heat; then through any broken opening of the window, flying brands may cause pilot ignition of combustibles just inside the window such as curtaining, wood panelling or stored goods.

\section{FLAME CONTACT}

The danger range for flame contact depends on the dimensions of the projecting flame. Law and O'Brien's (1983) steel building design guide provides a detailed method of calculating flame size, height, horizontal projection distance and temperature with and without wind conditions. Butcher ana Parnell (1983) give examples of horizontal flame projections. In general, it can be said that under no wind conditions, flames will project a distance varying from half the window height for long windows to $1 \frac{1}{2}$ times the window height for square windows.

The control of ignition between buildings depends on the selected design values of the flame projection distance $P$ and the specified protected limiting distance $\mathrm{Lx}_{x}$. The values of $\mathrm{P}$ and $\mathrm{L}_{\mathrm{x}}$ vary between different codes and are not always easy to determine from the codes themselves. For example, the British system seems to work from face-to-face of buildings, that is $P=0 \mathrm{~m}$ and $\mathrm{L}_{\mathrm{X}}=0 \mathrm{~m}$. The Canadian system seems to work from flame front to building face using $P=1.5 \mathrm{~m}$ and $I_{x}=1.2 \mathrm{~m}$.

$4 \times 4$ matrix diagrams can be drawn up to illustrate the effect of varying values of $P$ and $L_{X}$. For example, where $P=2 \mathrm{~m}, I_{X}=0 \mathrm{~m}$ and ordinary glazing is used, it can be shown that flame contact will occur in 6 out of the 16 situations. If "approved" closures are used in the external walls of the O-buildings and the $\mathrm{N}$-buildings, flames will both be prevented from gaining exit via the owner's openings and gaining entry via the neighbour's openings. The probability of remaining flame contacts then depends on the value of the protected limiting distance $L_{x}$ as set by the Fire code writers. For example, for $P=2 \mathrm{~m}$ and $L_{X}=1 \mathrm{~m}, \mathrm{Fig} .3$ shows that the number of flame contacts reduces to 1 in 16 cases and then only against a fire window (case 2/0). Mirror-imaging only occurs in 4 cases, namely the $0 / 0,1 / 1,2 / 2$ and $3 / 3$ situations. Some of the non-mirrox situations are unsafe. For example, situations $0 / 1$ when reversed introduces a radiation hazard in that the area of openings for the $\mathrm{N}$-building are set for $\mathrm{R}=2 \mathrm{~m}$, whereas in fact $\mathrm{R}=1 \mathrm{~m}$, thereby increasing the received radiation levels inside the O-building. Similarly in situation 2/3, the N-building "thinks" $R=4 \mathrm{~m}$, when in fact $\mathrm{R}=3 \mathrm{~m}$. Where $\mathrm{P}=2 \mathrm{~m}$ and $\mathrm{L}_{\mathrm{X}}=2 \mathrm{~m}$, flame contact occurs in none of the 16 situations listed, $0 / 1$ remains unsafe as in Eig. 3, but $2 / 3$ improves.

\section{PROJECTING FLAME TEMPERATURES}

A flame projecting outside a window can radiate heat back onto the wall directly behind the rising flame, to adjacent external structural members, and to a neighbouring building. Law and 'Brien's (1983) design method is derived from the expression $t_{f}=L /\left(A_{W} A_{T}\right)^{\frac{3}{2}}$, where $t_{f}=$ effective fire resistance time in minutes; $I=$ total fire load in $\mathrm{kg} ; \mathrm{AW}_{\mathrm{W}}=$ ventilation (window) area in square metres; and $\mathrm{A}_{\mathrm{T}}=$ area of fire compartment surfaces, but excluding $A_{W}$ in square metres (Law (1971)). The design method suggests that if the levels of flame and compartment temperature reached are proportional to time, then the compartment radiation level is also proportional to time.

Butcher and parnell (1983) give examples of flame tempexatures for six window sizes, ranging from $3000 \mathrm{C}$ to $6000^{\circ} \mathrm{C}$ or averaging $450^{\circ} \mathrm{C}$ for a compartment temperature of $11000 \mathrm{C}$. Keough (1963) suggests flame temperatures of 850,1000 and $1250^{\circ} \mathrm{C}$ should be used for design purposes corresponding to 
兽

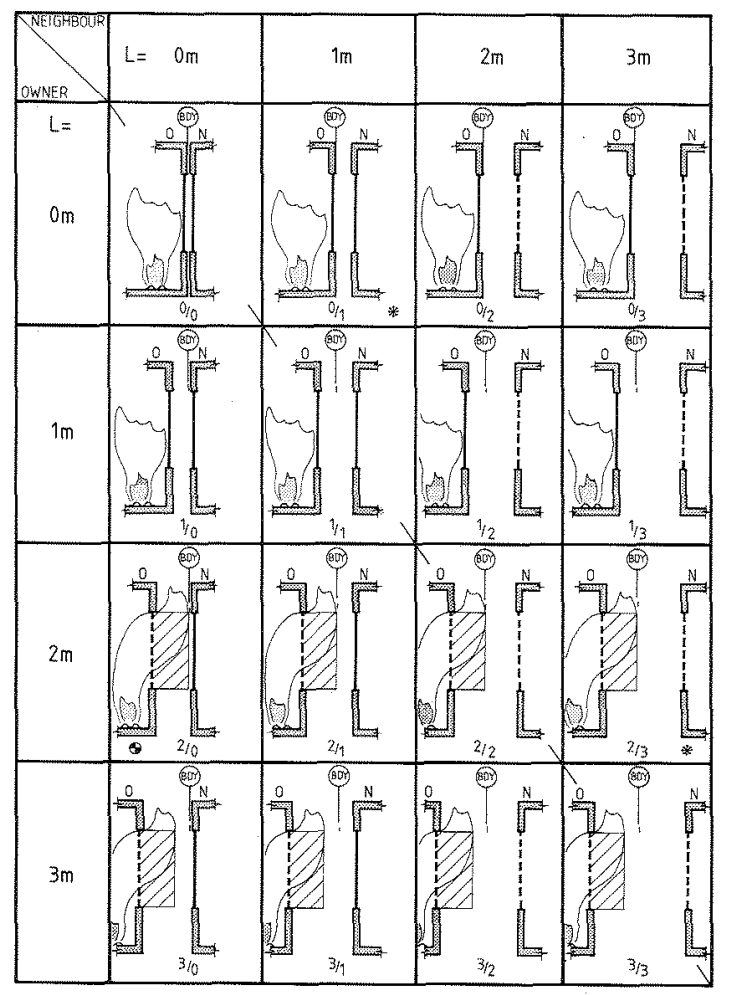

FIG.3. ILLUSTRATING FLAME CONTACT FOR $P=2 \mathrm{~m} \& \quad L \mathrm{~L}=1 \mathrm{~m}$ FLAME CONTACT REDUCES TO 1 OUT OF 16 CASES (MARKED $\theta$ ) 2 CASES ARE ALSO UNSAFE FROM RADIATION HAZARD WHEN $O \& N$ ARE REVERSED (MARKED*)

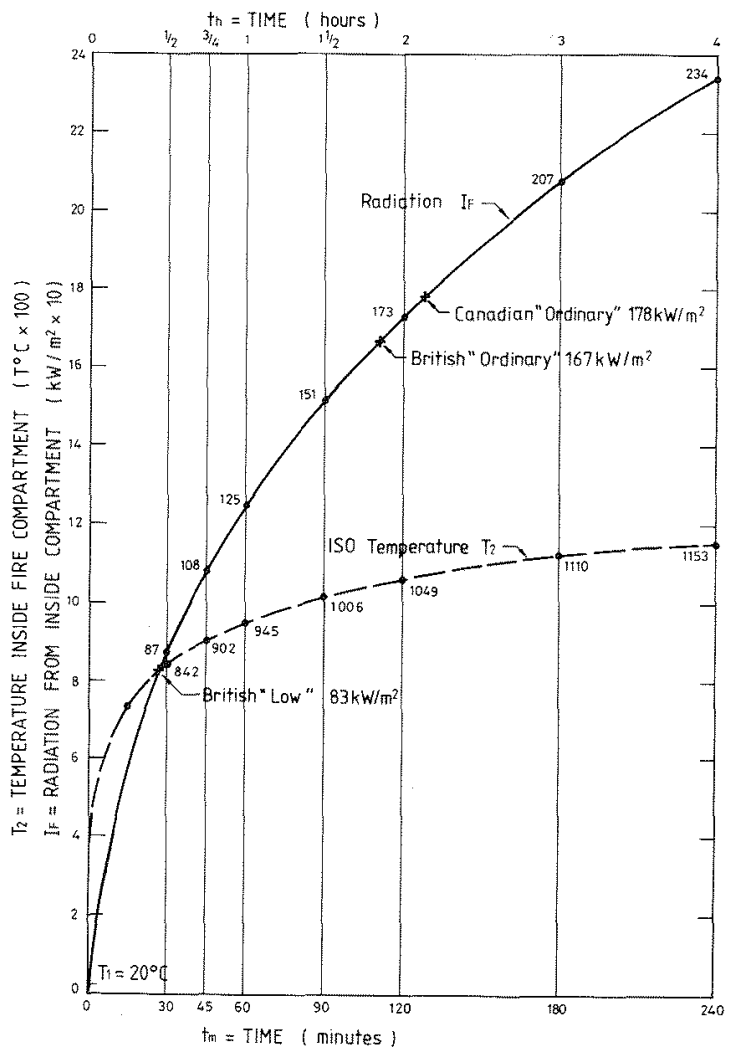

FIG. 4 VALUES FOR ISO TEMPERATURE $7_{2}$ AND CORRESPONDING RADIATION IF VERSUS TIME + FOR A FIRE COMPARTMENT 
effective radiation levels of $83.6,150$ and $300 \mathrm{kw} / \mathrm{m}^{2}$. For the purpose of fire separation distance an average projecting flame temperature of $600{ }^{\circ} \mathrm{C}$ could be assumed as reasonable for all compartments where temperatures range from $842^{\circ} \mathrm{C}$ (for $\frac{1}{2}$ hour FRR) to $1153^{\circ} \mathrm{C}$ (for 4 hour FRR).

\section{EMISSIVITY}

The intensity of radiant heat energy given off by a heated object depends on its emissivity $\varepsilon$. The perfect emittex is a "black" body and has an emissivity of unity. A fire compartment when heated acts as a cavity radiator with holes in it and thus approximates a "black" body with an emissivity of 1.00 . On the other hand, the emissivity of flames emerging from openings depends on the type of fuel, the type and size of particles burning within the flame, and the thickness of the flames. For building fires, Law and O'Brien (1983) in their design Table 9 list a range of emissivities for flame thickness. When required for the purpose of fire separation design, compartment emissivity could be assumed as 1.00 and flame enissivity as 0.45 for $2 \mathrm{~m}$ flame thickness.

\section{CONFIGURATION FACTORS}

The intensity of radiant energy $I_{R}$ falling on a surface remote from the emitter can be found by using an appropriate "configuration" factor on which takes into account the geometrical relationship between the emitter and receiver. For external building facades a rectangular radiator $F$ is assumed of height $H$ and width $W$, which in turn is divided into four equal rectangles $A, B, C$ and $D$. The configuration $\phi_{A}$ for rectangle $A$ is taken perpendicular to the central corner of rectangle $A$. Similarly for $B, C$ and D. This method of presentation allows advantage to be taken of the fact that configuration factors are additive. The value of $\phi_{A}$ would vary from 0 to 0.25 , and the value of $\phi_{n}$ from 0 to 1.0. The total configuration factor $\phi_{n}$ for the whole rectangle is made up of the individual configuration factors for rectangles A, B, C and D thus:-

$\phi_{\mathrm{D}}=\phi_{\mathrm{A}}+\phi_{\mathrm{B}}+\phi_{\mathrm{C}}+\phi_{\mathrm{D}}=4 \phi_{\mathrm{A}}$

Drysdale (1983 and 1985) illustrates graphical methods of determining $\phi_{A}$. Law and o'Brien (1983) use the following formula for a receiver parallel to the radiator:-

$\phi_{\mathrm{A}} \quad \frac{1}{360}\left[\frac{x}{\left(1+x^{2}\right)^{\frac{1}{2}}} \cdot \tan ^{-1} \frac{y}{\left(1+x^{2}\right)^{\frac{1}{2}}}+\frac{y}{\left(1+y^{2}\right)^{\frac{1}{2}}} \cdot \tan ^{-1} \frac{x}{\left(1+y^{2}\right)^{\frac{1}{2}}}\right]$

where $x=H_{A} / R=H / 2 R ; y=W_{A} / R=W / 2 R ; \quad H_{A}=$ height of quarter rectangle $\mathrm{A}=\mathrm{H} / 2 ; \quad \mathrm{W}_{\mathrm{A}}=$ width of quarter rectangle $\mathrm{A}=\mathrm{W} / 2 ; \mathrm{R}=$ radiation distance between emitter and receiver; and $\tan ^{-1}=$ degree mode. Eqs. (1) and (2) do not depend on the use of watex and hence can be safely applied in nonwater regions such as rural areas, small islands and frozen climates.

\section{EMITTED HEAT RADIATION}

Increasing the separation distance between buildings reduces the radiation hazard, but for a given separation distance the intensity of received radiation $I_{R}$ on the non-burning building depends on the intensity of emitted radiation $I_{E}$ from the burning building. The maximum fire compartment temperature $\mathrm{T}_{2}$ in degrees Centigrade can be determined in a number of ways from a standard time-temperature formula such as BS 476 or ISO 834 as follows:- 
The radiant energy flux $I_{F}$ present inside a fire compartment can be considered to be proportional to the difference in temperature of the fire compartment $T_{2}$ and its surrounding $T_{1}$ in degrees Kelvin thus:-

$I_{F}=\varepsilon \sigma\left(T_{2}{ }^{4}-T_{1}^{4}\right) \quad \mathrm{kW} / \mathrm{m}^{2}$

IF can be considered as radiating in all directions inside the fire compartment at once and can therefore be expected to be the same value IEI just inside any opening as illustrated in Fig. 1 , thus $I_{E 1}=I_{F}$. By using Eqs. (3) and (4), values of $I_{E l}$ corresponding to standard fire resistance rating times can be determined as shown in Fig. 4.

Arising from the enitted radiation just inside the opening $\mathrm{I}_{\mathrm{EI}}$, the question arises as to what critical value of emitted radiation $I_{E C}$ should be used outside the building. This will depend on whether the glazing remains in position or not. Fig. 1 illustrates $I_{E 2}$ as the critical value for ordinary windows and $\mathrm{I}_{\mathrm{E} 4}$ for fire windows. Grubits (1985) reports that when the glass remains in position, the radiation is reduced to a value between $7 \%$ and $46 \%$ of the impressed radiant heat. Thus a radiation reduction factor $k_{l}$ of 0.50 through wired glass would appear to be a reasonable design assumption. Providing the glass remains in position, this reduced radiation effect can be utilised in building separation calculations.

When ordinary glazing cracks and falis out of the openings, flames commence to project outside the building. The flame area greater than the openings are ignored and the radiating openings are assumed to be acting, not at the face of the building wall, but at a distance out from the building face equal to the flame projecting distance P. Law (1971) sets out the reasons why radiation from projecting flames are usually neglected in fire separation calculations. This is considered to be a conservative adjustment which greatly simplifies the design procedure for radiation distance calculations.

For ordinary glazing, $k_{1}=1.0$ and thus $I_{E C}=I_{E 2}=I_{E 1}=I_{F}$. For Fire resistant glazing $\mathrm{k}_{1}=0.50$ and thus $\mathrm{I}_{\mathrm{EC}}=\mathrm{I}_{\mathrm{E} 4}=0.5 \mathrm{I}_{\mathrm{E} 1}=0.5 \mathrm{I}_{\mathrm{F}}$. The above values for $I_{E C}$ refer to the unit radiation from one opening. Most external walls have a number of openings, but the problem can be reduced to that of a single radiator, termed the "enclosing rectangle" which is considered as emitting radiation over its whole area at a reduced intensity $I_{E 3}$ (or $I_{E 5}$ ) (refer Figs. 1 and 2). The "enclosing rectangle" should be taken for a number of selected large and small cases as shown on Fig. 5 , the worst

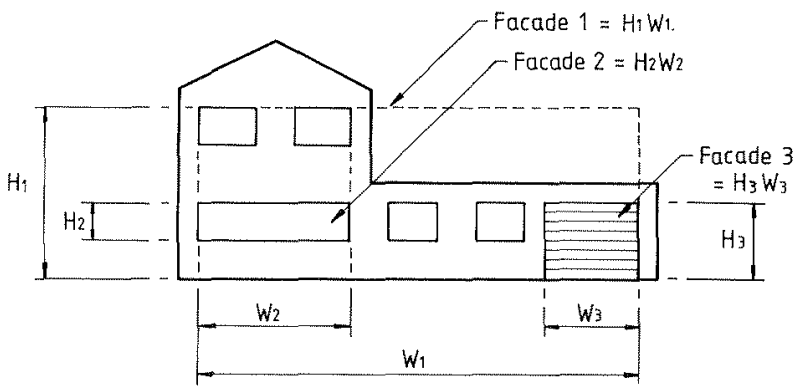

FIG. 5 ILLUSTRATION OF VARIOUS TYPES OF FACADES FROM WHICH SEPARATION DISTANCES ARE CALCULATED 
case applying. The reduction factor $\mathrm{k}_{\mathrm{v}}$ is taken as the ratio of the sum of the areas of all the vertical openings in the wall $A_{V}$ to the total area of the enclosing rectangle $\mathrm{A}_{\mathrm{E}}=\mathrm{H} \times \mathrm{W} . \mathrm{kV}$ is also equal to the ratio between $\mathrm{I}_{\mathrm{E} 3}$ (or $\mathrm{IE}_{\mathrm{E}}$ ) and $\mathrm{I}_{\mathrm{EC}}$ thus:-

$k_{V}=\frac{A_{V}}{A_{E}}=\frac{I_{E} 3}{I_{E C}}$ or $\frac{I_{E} 5}{I_{E C}}$

\section{RECEIVED HEAT RADIATION}

When a neighbour's building receives heat radiation $I_{R}$, there is not only the hazard to any combustible matexial on the outside of the building $I_{R I}$, but also to the combustible contents in any rooms likely to receive radiation through glazed or unglazed openings $I_{R 3}$, or fire windows $I_{R 5}$. Refer to Figs. 1 and 2 which also show the received radiation just outside the openings as $I_{R 2}$ for ordinary windows and $I_{R 4}$ for fire windows. For design purposes the critical design value of received radiation $I_{R C}$ will be the least value of $I_{R 1}$, $I_{R 2}$ and $I_{R 4}$. In order to avoid ignition by received radiation, limits have to be set on the values of $I_{R C}$ depending on whether the situation is likely to be exposed to pilot ignition or spontaneous ignition. The critical design value $I_{R C}$ can be compared with the radiant energy $I_{R}$ received by a surface remote from a heated emitter as follows:-

$I_{\mathrm{R}}=\phi_{\mathrm{n}} \cdot I_{\mathrm{E} 3} \leq \mathrm{I}_{\mathrm{RC}}$

If the neighbour's building has a combustible material on the exterior walls, pilot ignition of $12.5 \mathrm{~kW} / \mathrm{m}^{2}$ is the likely criteria. Thus for design purposes $I_{R C}=I_{R I}=12.5 \mathrm{~kW} / \mathrm{m}^{2}$. Ordinary glazing is likely to crack and fall out. This means the radiation reduction effect through ordinary glass cannot be relied on and pilot ignition of combustible materials just inside the openings must be used. The recommended radiant flux value based on pilot ignition should be $12.5 \mathrm{~kW} / \mathrm{m}^{2}$. Thus for design puxposes $I_{R C}=I_{R 2}=$ $I_{R 3}=12.5 \mathrm{~kW} / \mathrm{m}^{2}$. For fire resistant glazing likely to remain in position for the design duration period of the burning building fire, then a spontaneous ignition value such as $25 \mathrm{~kW} / \mathrm{m}^{2}$ or other selected value will apply for IR5 inside the window. And if $\mathrm{k}_{2}=0.50$ resulting in $50 \%$ radiation reduction through the fire window, the design value for $I_{R 4}$ outside the window can be twice $I_{R 5}$, that is $50 \mathrm{~kW} / \mathrm{m}^{2}$. Thus for design purposes $I_{R C}=I_{R 4}=$ $\mathrm{I}_{\mathrm{R} 5} / \mathrm{k}_{2}=50 \mathrm{~kW} / \mathrm{m}^{2}$.

The reason for selecting different reduction coefficients $\mathrm{k}_{1}$ and $\mathrm{k}_{2}$, is that while they may be the same for cases (a) and (d) as illustrated on Fig. 2, they will be different when cases (c) and (c) are being applied.

\section{DESTGN METHODS}

There are two methods available for the fire engineering design of separation between buildings depending on whether the required answer is to be in terms of the maximum permissible openings in the owner's building or the level of received radiation on the neighbour's building for a given set of owner's openings. In the first design method, the calculations are entered with FRR, $k_{1}, k_{2}, T_{1}, I_{R I}, I_{R 3}, I_{R 5}, I$ or $S, P, H$ and $w$. $I_{E C}$ is calculated through Eqs. (3) and (4). $I_{R C}$ is taken as the least value of $I_{R l}$, $I_{R 2}$ or $I_{R 4}$. $i_{n}$ is determined from Eqs. (1) and (2) after ascertaining the appropriate $R$. $\mathrm{A}_{\mathrm{E}}$ is determined from $\mathrm{H}$ and $W$. By combining Eqs. (5) and (6), the maximum permissible area of openings $A_{V}$ can then be calculated as:-

$A_{V}=\frac{A_{E} \cdot I_{R C}}{\phi n \cdot I_{E C}}$ $m^{2}$ 
In the second design method, the calculations are entered with FRR, $\mathrm{k}_{1}, \mathrm{~T}_{1}, \mathrm{~L}$ or $\mathrm{S}, \mathrm{P}, \mathrm{H}, \mathrm{W}$ and $\mathrm{A}_{\mathrm{V}}$. $\mathrm{IEC}_{\mathrm{EC}} \phi_{\mathrm{n}}, \mathrm{AE}_{\mathrm{E}}$ and $\mathrm{k}_{\mathrm{V}}$ axe calculated as above. The value of $I_{R}$ is determined and compared with $I_{R C}$ as follows:-

$I_{R}=k_{V} \cdot \phi_{n} \cdot I_{E C} \leq I_{R C} \quad \mathrm{~kW} / \mathrm{m}^{2}$

Eqs. (7) and (8) can be used to check existing fire codes providing the correct entry values can be identified. Fox instance, British Building Regulations (1985) appear to work from face-to-face of buildings with no al. lowances for flame projection or fire windows, i.e. $P=0 \mathrm{~m}, \mathrm{~L}_{\mathrm{x}}=0 \mathrm{~m}$ and FRR input values of $\frac{1}{2}$ and 2 hours respectively. The National Building code of Canada (1985) appears to work from flame front to face of building using $\mathrm{P}=1.5 \mathrm{~m}, I_{\mathrm{x}}=1.2 \mathrm{~m}$, and $\mathrm{FRR}$ input values of 2 and 7 hours respectively.

\section{CONCEUSTONS}

Five meanings for "distance" are defined for use in fire engineering design methods for separation between buildings. By making fire windows mandatory within a protected limiting distance $\mathrm{Lx}_{\mathrm{x}}$ from the boundary, flame contact danger through openings can be virtually eliminated. "Mirrorimaging" does not always produce safe solutions for radiation hazard, but critical situations can be readily checked. "Non mirror-image" situations including mixtures of fire windows on one building and ordinary windows on the other building can also be readily checked. Where fire windows are used and external cladding is non-combustible, spontaneous ignition values can be used in the design process. At least $50 \%$ reduction in radiation can occur through fire windows. Combined, these two facts can lead to considerable increases in traditional opening areas in external walls, not only where fire windows are compulsory, but also where they are voluntarily used beyond the protected limiting distance $L_{X}$.

The design method described herein not only offers more than the usual choice in the fire engineering design of extexnal walls, but can also be linked directly to the standard fire resistance ratings ranging fxom $\frac{1}{2}$ to 4 hours and also directly to fire compartment axea design methods. The design method is also readily adaptable to tables, graphs, and hand-held programmable calculators. It can be used not only to design new buildings, but also to check critical situations between existing buildings for both "mixror-image" and "non mirror-image" situations. The design methods do not rely on the use of water and are suitable for areas having little or no stored ox runing water such as rural areas, remote islands or frozen climates. Where running water is readily available for extinguishing or wetting down purposes, nominal concessions to design values would be reasonable.

\section{NOMENCLATURE}

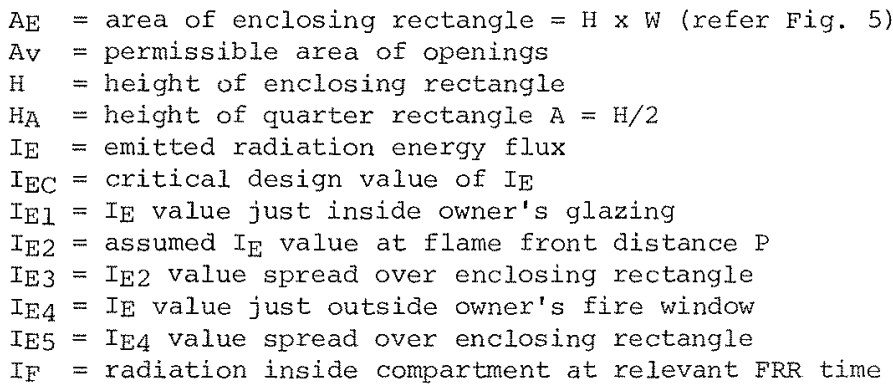

$\mathrm{m}^{2}$
$\mathrm{~m}^{2}$
$\mathrm{~m}$
$\mathrm{~m}$
$\mathrm{~kW} / \mathrm{m}^{2}$
$\mathrm{~kW} / \mathrm{m}^{2}$
$\mathrm{~kW} / \mathrm{m}^{2}$
$\mathrm{~kW} / \mathrm{m}^{2}$
$\mathrm{~kW} / \mathrm{m}^{2}$
$\mathrm{~kW} / \mathrm{m}^{2}$
$\mathrm{kw} / \mathrm{m}^{2}$
$\mathrm{kw} / \mathrm{m}^{2}$


$I_{R}=$ received radiation energy flux

$I_{R C}=$ critical design value of $I_{R}$

$I_{R}=$ pilot ignition $I_{R}$ for neighbour's cladding

$I_{R 2}=$ pilot ignition $I_{R}$ outside neighbour's ordinary glazing

$I_{R 3}=$ pilot ignition $I_{R}$ inside neighbour's ordinary glazing
$I_{R 4}=$ increased value of $I_{R 5}$ due to reduction factor $k_{2}$

$\mathrm{kW} / \mathrm{m}^{2}$

$I_{R 5}=$ spontaneous ignition $I_{R}$ inside neighbour's fire window

$k_{\mathrm{V}}=$ ratio between areas $=\mathrm{AV} / \mathrm{AE}$ or emitted radiations $=\mathrm{IE} 3 / \mathrm{I}_{\mathrm{EC}}$

$\mathrm{kl}=$ radiation reduction factor through owner's glazing

$k_{2}=$ radiation reduction factor through neighbour's glazing -

$I=$ limiting distance $(\mathrm{Fig} . \mathrm{I})=\frac{1}{2} \mathrm{~S}=\frac{1}{2}(\mathrm{R}+\mathrm{P})$

$I_{x}=$ protected limiting distance specified by Fire code m

$\mathrm{P}=$ flame projection distance (Fig. 1)

$\mathrm{R}=$ radiation distance (Fig. I)

$\mathrm{S}=$ separation distance $(\mathrm{Fiq}, 1)=(\mathrm{R}+\mathrm{P})$

$\mathrm{T}_{1}=$ ambient temperature, generally $20^{\circ} \mathrm{C}$ or $2930^{\mathrm{K}}$

$\mathrm{T}_{2}=$ fire compartment temperature as per Eq. (3)

$t_{m}=$ time

$W^{-}=$width of enclosing rectangle

$W_{A}=$ width of quarter rectangle $A=W / 2$

$\varepsilon=$ emissivity, generally 1.0

$\phi \quad=$ stefan-Boltzmann constant $=56.7 \times 10^{-12}$

$\phi_{\mathrm{A}}=$ configuration factor for quarter rectangle $\mathrm{A}$

$\phi_{n}=$ configuration factor for enclosing rectangle

\section{REFERENCES}

1. Butcher, E.G. and Parne11, A.C. (1983) - "Designing for Fire Safety" - John Wiley \& Sons, Chichester

2. Drysdale, D.D. (1983) - "Ignition : The Material, The Source and subsequent Fire Growth" - SFPE Technology Report 83-5.

3. Drysdale, D.D. (1985) .. "An Introduction to Fire Dynamics" - John Wiley \& Son, Chichester

4. Grubits, S.J. (1985) - "Developments in External Drencher Protections" Proceedings 10th National. Conference of Australian FPA "Technology \& Fire", Melbourne (sep. 85) pp 133-143.

5. Keough, J.J. (1963) - "Diagrams for the Approximate Assessment of Radiation Exposure Hazards from Fires in Buildings" - Commonwealth Experimental Building Station (National Building Techn. Centre) Sydney.

6. Law, Margaret (1963) - "Heat Radiation from Fires and Building Separation" Joint FRO, Fire Research Stat. Techn. Paper No. 5, HMSO, London.

7. Law, Margaret (1971) - "Prediction of Fire Resistance" - Proceedings of Symposium No. 5, HMSO, London

8. Law, M. and O'Brien, T. (1983) - "Fire Safe Structural Steel" American Iron and Steel Institute, Washington.

(The foregoing is a condensed paper. Copies of the full paper, tables, other matxix diagrams, or HP-4l-CV programmes axe available from the author on request.) 